Neurosurg Focus 24 (6):E8, 2008

\title{
Management of brain abscesses in children
}

\author{
James L. Frazier, M.D., Edward S. Ahn, M.D., And George I. Jallo, M.D. \\ Department of Neurosurgery, Johns Hopkins University, Baltimore, Maryland
}

\begin{abstract}
$\checkmark$ Brain abscesses occur infrequently but continue to be problematic for the pediatric neurosurgical community. The incidence of brain abscesses in children has not changed much, although individual reports may show an increase or decrease in the number of reported cases depending on the patient population studied. An increase could be attributed to earlier detection due to advancements in imaging modalities and/or to an increase in the number of children with immunodeficient states caused by AIDS, chemotherapy for malignant lesions, and immunosuppressive therapy for organ transplantation. A decrease in the incidence of brain abscesses could be attributed to practices such as antibiotic treatment for otitis media, sinusitis, and/or prophylactic antimicrobial treatment for congenital heart disease in children. The morbidity and mortality rates associated with brain abscesses have not changed dramatically in the antibiotic and imaging era, and their preferred management can vary among healthcare providers. These lesions have been successfully treated by neurosurgeons. The causes of brain abscesses are highly variable in children, which is also the case in adults, but the predisposing factors in the pediatric population differ in prevalence. Cyanotic congenital heart disease, hematogenous dissemination, contiguous infection, and penetrating traumatic injuries are the most common causes of brain abscesses in children. In this review, the authors discuss the causes and medical and surgical management of brain abscesses in children. (DOI: 10.3171/FOC/2008/24/6/E8)
\end{abstract}

\author{
KEY WORDS • brain abscess • craniotomy • pediatric neurosurgery • \\ stereotactic aspiration
}

$\mathrm{B}$ RAIN abscesses occur infrequently, with an incidence of 4 cases per million. In the pediatric population they are seen most often in children between 4 and 7 years of age.$^{51}$ Intracranial parenchymal abscesses are a consequence of invasion by infectious microorganisms secondary to hematogenous dissemination from a remote infection, the spread of a contiguous infection, foreign material introduced through a penetrating traumatic injury, or as a postoperative complication. In 1876 Macewen ${ }^{62}$ made the first diagnosis of a brain abscess in a child based on symptoms and the results of a neurological examination. A left frontal lobe abscess was found at the postmortem examination after the family had refused surgery. Prior to the introduction of CT, the delay in diagnosis contributed to high rates of death and complications. Subsequently, the advent of CT has aided in the diagnosis of brain abscesses, and the introduction of antibiotics has assisted in their management. ${ }^{64,83}$ The morbidity and mortality rates associated with brain abscesses have decreased but remain significant. ${ }^{68,98}$ The introduction of MR imaging has provided even greater anatomical detail, and similar to the effects of CT, has contributed to earlier diagnosis and better localization of the lesion. Imaging

Abbreviations used in this paper: $\mathrm{CN}=$ cranial nerve; $\mathrm{CT}=$ computed tomography; $\mathrm{MR}=$ magnetic resonance. technology may have contributed to an apparent increase in the incidence of brain abscesses due to earlier diagnosis, but opportunistic microorganisms also play a role as more children become susceptible to infection because of chemotherapy for neoplastic processes, organ transplantation, and AIDS. Moreover, the prevalence of the predisposing factors in children differs from that in adults.

In the present study we will provide a broad overview of intracerebral abscesses in children. Predisposing factors, clinical presentation, diagnosis, operative and nonoperative management, and prognosis will be discussed.

\section{Predisposing Factors}

Various predisposing factors can lead to brain abscesses in children, and their prevalence in this population differs from that in adults (Table 1). The cause of the abscess is unknown in $15-30 \%$ of cases. ${ }^{10,19,107,108}$ Common predisposing factors include hematogenous dissemination, contiguous infection, and penetrating head injuries. Infants and toddlers are more susceptible than other age groups to brain abscesses arising as complications of bacterial meningitis or bacteremia. ${ }^{21,53,80}$ This lesion has also been reported as a complication of neurosurgical procedures in $8-10 \%$ of cases of brain abscesses. ${ }^{110} \mathrm{~A}$ leading cause of intracranial abscess formation in developing countries is chronic suppurative otitis media. ${ }^{23,49,56}$ In addition, cyanotic congenital 
TABLE 1

Predisposing factors for brain abscesses in children

\begin{tabular}{|c|c|}
\hline Route of Infection (\%) & Pathogen \\
\hline \multicolumn{2}{|l|}{ hematogenous dissemination } \\
\hline congenital heart disease (30-34) & S. aureus, aerobic \& microaerophilic streptococci, Haemophilus spp. \\
\hline pulmonary infection $(0.7-9.8)$ & aerobic \& anaerobic streptococci, Nocardia, anaerobic gram-negative bacilli, \\
\hline endocarditis $(9-10)$ & Fusobacterlum, \& Actınomyces \\
\hline endocarditis (9-10) & S. aureus, aerobic \& microaerophilic streptococci \\
\hline bacteremia (8) & S. aureus, aerobic \& microaerophilic streptococci, \& anaerobic gram-negative bacilli \\
\hline immunodeficiency (12) & $\begin{array}{l}\text { anaerobic gram-negative bacilli, Aspergillus, Candida spp., Enterobacteriaceae, Nocardia, Cryptococcus, } \\
\text { T. Gondii, Mucorales, Listeria monocytogenes, \& mycobacterium }\end{array}$ \\
\hline skin folliculitis (1-3) & S. aureus, \& Streptococci spp. \\
\hline osteomyelitis & S. aureus, Enterobacter, Streptococci spp., \& Haemophilus \\
\hline $\begin{array}{l}\text { pulmonary foreign bodies } \\
\text { from aspiration }\end{array}$ & aerobic \& anaerobic streptococci, anaerobic gram-negative bacilli, Nocardia, Fusobacterium, \& Actinomyces spp. \\
\hline \multicolumn{2}{|l|}{ spread of contiguous infection } \\
\hline sinusitis $(6-8)$ & S. aureus, Streptococci spp., Pseudomonas, Fusobacterium, Enterobacteriaceae, Bacteroides, \& Haemophilus spp. \\
\hline otitis media, mastoiditis (6-10) & aerobic \& anaerobic streptococci, Pseudomonas, Enterobacteriaceae, Provetella, \& Bacteroides spp. \\
\hline meningitis $(12-36)$ & Staphylococci, gram-negative bacilli, Streptococci, Listeria, \& Haemophilus spp. \\
\hline penetrating cranial injury (4-13) & Staphylococci, Enterococci, Mycobacterium, Bacteroides spp., \& Clostridium \\
\hline $\begin{array}{l}\text { complication of neurosurgical } \\
\text { procedure }(8-10)\end{array}$ & Staphylococci, Pseudomonaceae \& Enterobacteriaceae \\
\hline unknown origin $(15-30)$ & unknown \\
\hline
\end{tabular}

heart disease is one of the more common causes of brain abscesses in children.

The prevalence of brain abscesses in children with cyanotic congenital heart disease is $6-51 \% .{ }^{19,27,35,54,55,91,102,108}$ Of patients diagnosed with a brain abscess, $30-34 \%$ have underlying heart defects. ${ }^{1,19,82,91,102,108,110}$ Pronounced right-toleft shunting secondary to cardiac defects increases the risk of brain abscesses via paradoxical emboli..$^{78,99}$ Tetralogy of Fallot, ${ }^{19,102,108}$ transposition of the great vessels, atrial septal defects, ventricular septal defects, and the Eisenmenger complex are other cardiac anomalies known to predispose children to brain abscesses. Although rare, a persistent left superior vena cava may also lead to a brain abscess because in patients with this abnormality, venous blood from the left arm and left side of the head drains directly into the left atrium, resulting in a right-to-left shunt. ${ }^{26}$ Endocarditis, bacteremia, chronic pulmonary infections, bronchiectasis, immunodeficiency, osteomyelitis, skin pustules, and folliculitis are other sources of hematogenous dissemination that can lead to metastatic brain abscesses in children. ${ }^{19,82}$ Available data indicate that the underlying cause of brain abscesses is endocarditis in 9-10\% of patients, bacteremia in $8 \%$, immune deficiency in $12 \%$, skin follicultis in $1-3 \%$, and pulmonary infection in $0.7-9.8 \% .^{1,19,82,102,108,110}$ Pulmonary foreign bodies aspirated by children can lead to hematogenous seeding of the brain with bacteria and the subsequent development of abscesses.

The contiguous spread of infection into the cerebral parenchyma is another significant cause of brain abscesses in children. Otitis media, sinusitis, mastoiditis, dental infections, and meningitis are predisposing factors. Brain abscesses are a sequela in 6-8\% of sinusitis cases and in 6$10 \%$ of otitis media and mastoiditis cases. ${ }^{19,110}$ The intracranial extension of infections represents a serious complication of these pathological processes. Temporal lobe or cerebellar abscesses can occur by direct extension of infection via the tegmen tympani, or translabyrinthine spread in otitis media or mastoiditis. Frontal or temporal lobe abscesses can occur with direct spread of infection caused by paranasal sinusitis. It has been hypothesized that the anatomy of the paranasal sinuses provides a favorable environment for the intracranial extension of infection. Venous mucosal drainage occurs through the small diploic veins extending through the bony sinus wall, which communicate with the venous plexuses of the dura mater of the inner table, the periorbita for the orbital plate, and the cranial periosteum for the outer table. This connection between the extra- and intracranial venous systems may account for the transmission of infection through a retrograde thrombophlebitis. ${ }^{3,36,40,70}$ Furthermore, meningitis is an underlying cause of intracranial abscesses in 12-36\% of cases, particularly in infants and toddlers. ${ }^{19,27,84,108}$

Penetrating head injuries also make children susceptible to intracerebral abscess formation, because retained debris and/or bone fragments can serve as a nidus of infection. Approximately $4-13 \%$ of brain abscesses in children are a result of cranial injuries. ${ }^{19,28,108}$ For example, many children have sustained penetrating ocular injuries as a result of experimenting with sharp objects such as pencils and sticks, and intracranial extension may lead to an abscess. ${ }^{4,32,43}$ The incidence of brain abscesses secondary to penetrating cranial injuries in children has been reported to range from 4.8 to $16 \% .^{19,27,102,108}$

Shunt infection is a known risk of hardware placement for hydrocephalus. Although a rare phenomenon, there have been reports of brain abscesses in children that result from colonic perforation and ascending shunt infection..$^{31,38 \text {, }}$ 48,76,92 Recently, Ersahin and Yurtseven ${ }^{29}$ reported on the case of a child in whom a brain abscess resulted from an untreated shunt infection rather than colonic perforation.

\section{Clinical Presentation and Diagnosis}

The clinical signs and symptoms in children with brain abscesses are contingent on the location and size of the lesion, presence of surrounding edema, virulence of the 
TABLE 2

Histopathological and imaging findings during the stages of abscess formation*

\begin{tabular}{|c|c|c|c|c|}
\hline \multirow[b]{2}{*}{ Stage } & \multirow{2}{*}{$\begin{array}{l}\text { Interval } \\
\text { (Days) }\end{array}$} & \multirow[b]{2}{*}{ Pathological Characteristics } & \multicolumn{2}{|l|}{ Imaging Findings } \\
\hline & & & CT & MR \\
\hline early cerebritis & $1-3$ & $\begin{array}{l}\text { ill-defined lesion secondary to brain infection w/ } \\
\text { infiltration by inflammatory cells \& vasodilation; } \\
\text { peripheral edema }\end{array}$ & $\begin{array}{l}\text { poorly defined hypodense area } \\
\text { or normal findings; minimal } \\
\text { CE may be apparent }\end{array}$ & edema more evident \\
\hline late cerebritis & $4-9$ & $\begin{array}{l}\text { peripheral ring of macrophages, inflammatory cells, } \\
\text { \& fibroblasts surrounding a central necrotic area }\end{array}$ & $\begin{array}{l}\text { early patchy enhancement progressing } \\
\text { to ring enhancement later in this stage }\end{array}$ & $\begin{array}{l}\text { ring enhancement } \\
\text { visualized early }\end{array}$ \\
\hline early capsule formation & $10-14$ & $\begin{array}{l}\text { necrosis \& liquefaction, initial formation of } \\
\text { collagenous capsule }\end{array}$ & distinct CE of thin-walled capsule & \\
\hline late capsule formation & $>14$ & fully formed, thick collagenous capsule & & \\
\hline
\end{tabular}

* Abbreviations: $\mathrm{CE}=$ contrast enhancement.

infectious microorganisms, and signs of infection. Fever has been shown to be an early indicator of this infectious process in 30-70\% of children. ${ }^{102,108}$ Some authors have reported fever, headache, seizures, and emesis as the predominant symptoms in children with brain abscesses. ${ }^{42}$, 46,102,108 An altered level of consciousness may be present. Intraventricular rupture of the abscess or herniation may be indicated by exacerbation of a headache or a decline in the child's Glascow Coma Scale score, particularly in the context of meningeal signs. ${ }^{65,88}$ Neonates frequently present with signs of infection and increased intracranial pressure, seizures, and increased head circumference with bulging fontanelles. ${ }^{21,80}$ Additionally, children with brainstem abscesses typically present with fever and headache early in the infectious course, and paresis and cranial nerve palsies subsequently develop, especially involving CNs III, VI, and VII. ${ }^{99}$ Classic brainstem syndromes are not frequently observed because the lesions are more likely to elongate into the brainstem than expand laterally. ${ }^{16,78,99,106}$

The location of the abscess determines the focal neurological signs, which can include paresis, visual field deficits, $\mathrm{CN}$ palsies, nystagmus, and/or cerebellar ataxia. Papilledema has been reported in $41-70 \%$ of cases. ${ }^{42,108}$ The incidence of hemiparesis has been shown to be higher in children than in adults, which was demonstrated to be the result of a higher frequency of metastatic abscesses seeding eloquent areas of brain. ${ }^{19}$ Moreover, larger abscesses may be associated with a significant mass effect and vasogenic edema. This may cause symptoms related to increased intracranial pressure, impending herniation, and/or neurological deficits from deletrious effects on adjacent eloquent cortex.

Peripheral leukocytosis, an elevated erythrocyte sedimentation rate, and elevated C-reactive protein can be found in most children with brain abscesses. A mass effect associated with brain abscesses is a strong contraindication for lumbar puncture, and published reports provide a consensus that cerebrospinal fluid findings are nonspecific. ${ }^{19}$ Blood cultures are infrequently positive for bacteria, as these results depend on the source of the infection, such as bacteremia, but should be obtained in all cases prior to antibiotic treatment. ${ }^{18}$

\section{Imaging Diagnosis of Brain Abscesses}

Computed tomography imaging has proved a valuable asset in the diagnosis of brain abscesses. This imaging modality allows localization of the abscess and demonstration of any associated edema or mass effect. Depending on the stage of the abscess, the lesion typically has a hypodense center with ring enhancement on contrast-enhanced studies. The sensitivity of CT has been shown to be between 95 and $99 \%$, and the specificity is decreased because of the difficulty in differentiating these lesions from other pathological processes such as tumors, cysticercosis, tuberculomas, or some vascular lesions. ${ }^{47,67,78,107}$ In cases in which the diagnosis is questionable, radiolabeled leukocyte scanning can be utilized. There have been reports of good diagnostic accuracy with this modality. ${ }^{6,75}$

Magnetic resonance imaging can be used to demonstrate even more anatomical detail and with superior resolution than CT scanning. Abscesses appear slightly hypointense on T1-weighted and hyperintense on T2-weighted images. On contrast-enhanced T1-weighted images, the lesion has a hypointense center and ring enhancement. Similar to CT, this imaging modality's specificity may be compromised in differentiating abscesses from other lesions with similar imaging characteristics. The advantages of MR imaging over CT include better differentiation of edema from liquefactive necrosis, greater sensitivity for early satellite lesions, and more sensitivity in the detection of early cerebritis. ${ }^{19,88}$ Diffusion-weighted imaging has been shown to be a useful additional diagnostic modality in identifying brain abscesses..$^{13,30,57,69,79}$ Restricted diffusion in brain abscesses has been assumed to be a consequence of inflammatory cells, necrotic debris, and the viscosity of the purulent material contained within the abscess; however, Mishra et al. ${ }^{69}$ showed that viable cell density is the main biological parameter responsible for restricted diffusion in brain abscesses.

\section{Staging and Pathogenesis}

An animal model that resembles the pathophysiology in humans was examined on $\mathrm{CT}$ and used to track the stages of abscess development (Table 2). ${ }^{11,25}$ During the first 3 days of infection in the early cerebritis stage, an inflammatory response occurs with developing central necrosis and peripheral edema. The area is not well defined, and a CT scan may demonstrate normal findings, a hypodense area, or minimal enhancement with contrast addition. Between Days 4 and 9 of the infection, the late cerebritis stage oc- 
curs, and the central necrotic area is ringed with inflammatory cells. On CT scans, the early part of this stage is represented by patchy enhancement that develops into an enhancing ring later in the stage. The early capsule stage usually occurs between Days 10 and 14 with the formation of a distinct, thin-walled capsule of fibroblasts. On CT scans, a thin-walled capsule will show enhancement with the addition of contrast agent. Finally, late capsule formation stage occurs after Day 14, and the abscess has a thickened capsule that is represented by a bright, enhancing fibrotic capsule on CT.

\section{Microbiological Characteristics}

In addition to clinical and imaging data, the attainment of material from the lesion via either stereotactic aspiration or craniotomy can play a significant role in the diagnosis of brain abscesses. The microbial pathogens involved in the formation of brain abscesses vary and depend on the underlying source of infection. Gram-positive cocci such as Staphylococci, Streptococci, and Peptostreptococci spp. are the most common causative agents found in pediatric brain abscesses, followed by gram-negative bacilli, including Klebsiella, Escherichia coli, Salmonella, Bacteroides, Haemophilus, and Proteus spp. 10,19,27,100,102,108,110 The authors of a recent report noted that Citrobacter was found predominantly in neonates, while fungal pathogens were found more frequently in immunocompromised patients. ${ }^{37}$

\section{Surgical and Medical Management of Abscesses}

There have been no randomized, controlled trials of the various treatments for brain abscesses. Available information for treatment options is therefore not based on Class I data, with the possible exception of experimental data concerning corticosteroids. ${ }^{73,77}$ The management of brain abscesses may be influenced by the neurological status of the patient, the location of the abscess, the number and size of the abscesses, and the stage of abscess formation. ${ }^{59,61,91} \mathrm{In}$ the following sections we discuss the various treatment options for brain abscesses.

\section{Medical Management}

Brain abscesses in children should be managed by a multidisciplinary team that includes neurosurgeons and infectious disease practitioners. Systemic treatment with antibiotic agents plays a critical role in the treatment of these lesions. Patients usually receive a minimum 6- to 8-week course of intravenous antibiotics, which may be prolonged depending on the clinical context, such as in immunocompromised patients. Empiric antibiotic treatment with broadspectrum agents is usually started until intraoperative cultures can be obtained, allowing tailoring of the antimicrobial agents to the identified pathogens. If possible, antibiotics should be held until after surgery to reduce the possibility of a sterile culture obtained intraoperatively.

In patients who are treated by nonsurgical means only, specimens for culture will not be available. These include patients with surgically inaccessible lesions, early cerebritis, multiple small abscesses, or medical comorbidities that would classify the patient as high risk. ${ }^{19,108}$ Therefore, broad-spectrum antibiotics would be needed in these cases in an attempt to target several microorganisms. Serial imag- ing studies are conducted to assess the effectiveness of antibiotic therapy.

Corticosteroid use in the management of brain abscesses is controversial because steroids are known to inhibit the immune responses that play a role in limiting brain abscesses. ${ }^{84}$ The use of steroids is generally considered indicated when there is considerable mass effect secondary to significant cerebral edema leading to neurological deficits and/or impending herniation. ${ }^{107}$

\section{Surgical Management}

Stereotactic Aspiration. Operative management provides therapeutic and diagnostic benefits in patients with brain abscesses. ${ }^{19}$ There is relief of mass effect for larger, encapsulated abscesses, and cultures can be obtained. Typically, abscesses $>2.5 \mathrm{~cm}$ require surgical intervention. Imageguided stereotactic aspiration with antibiotic irrigation of the abscess cavity is a treatment modality that can be performed in a minimally invasive manner. Stereotactic aspiration can be conducted at any stage of evolution of the abscess, and a biopsy may yield positive cultures in the early cerebritis stage. ${ }^{61}$ This technique allows access to multiple and deep-seated abscesses, has a low complication rate, permits a minimal craniotomy, and allows multiple aspirations, if needed. ${ }^{5,17,96}$ Stereotactic aspiration has been demonstrated to have a diagnostic yield of $95 \% .^{90}$ Although minimally invasive, stereotactic aspiration is not without risk, including the development of an intracerebral hematoma and the rupture of the abscess into the ventricle or subarachnoid space. ${ }^{19}$

Craniotomy. Image-guided stereotactic craniotomy for extirpation of the abscess is considered beneficial in some cases of fungal or multiloculated abscesses, and in cases of failed resolution after multiple aspirations..$^{19}$ In some cases, the abscess can be drained under ultrasonographic guidance after the craniotomy is performed (Fig. 1). If the abscess is superficial and located close to the surface of the brain, a small craniotomy or bur hole may be used for abscess drainage (Fig. 2). Brain abscesses secondary to traumatic head injuries should be considered strongly for surgical excision because of the possibility of retained foreign bodies and/or bone fragments. ${ }^{81}$ Disadvantages to a craniotomy include its lack of suitability for lesions of the eloquent cortex, abscesses in the cerebritis stage, or those in children considered surgically high risk. ${ }^{86}$

Moreover, intraventricular rupture of an abscess, evident due to hydrocephalus and enhancement of ventricular walls, requires surgical debridement, ventricular drainage, and intraventricular and systemic antibiotic treatment.19,112 Alterations in the level of consciousness may herald impending herniation and should prompt surgical drainage of the abscess to alleviate mass effect. ${ }^{19,24}$

Neuroendoscopy. Neuroendoscopic drainage of brain abscesses is another possible treatment for brain abscesses. This technique allows the neurosurgeon to inspect and directly view the aspiration of the purulent collection, unlike stereotactic aspiration in which there is a lack of direct visual control. ${ }^{33,41,50,60}$ In addition, multiloculated abscesses could possibly be treated with the endoscopic technique. Recently, Longatti et al. ${ }^{60}$ reported that neuroendoscopic drainage of 4 brain abscesses did not differ significantly 

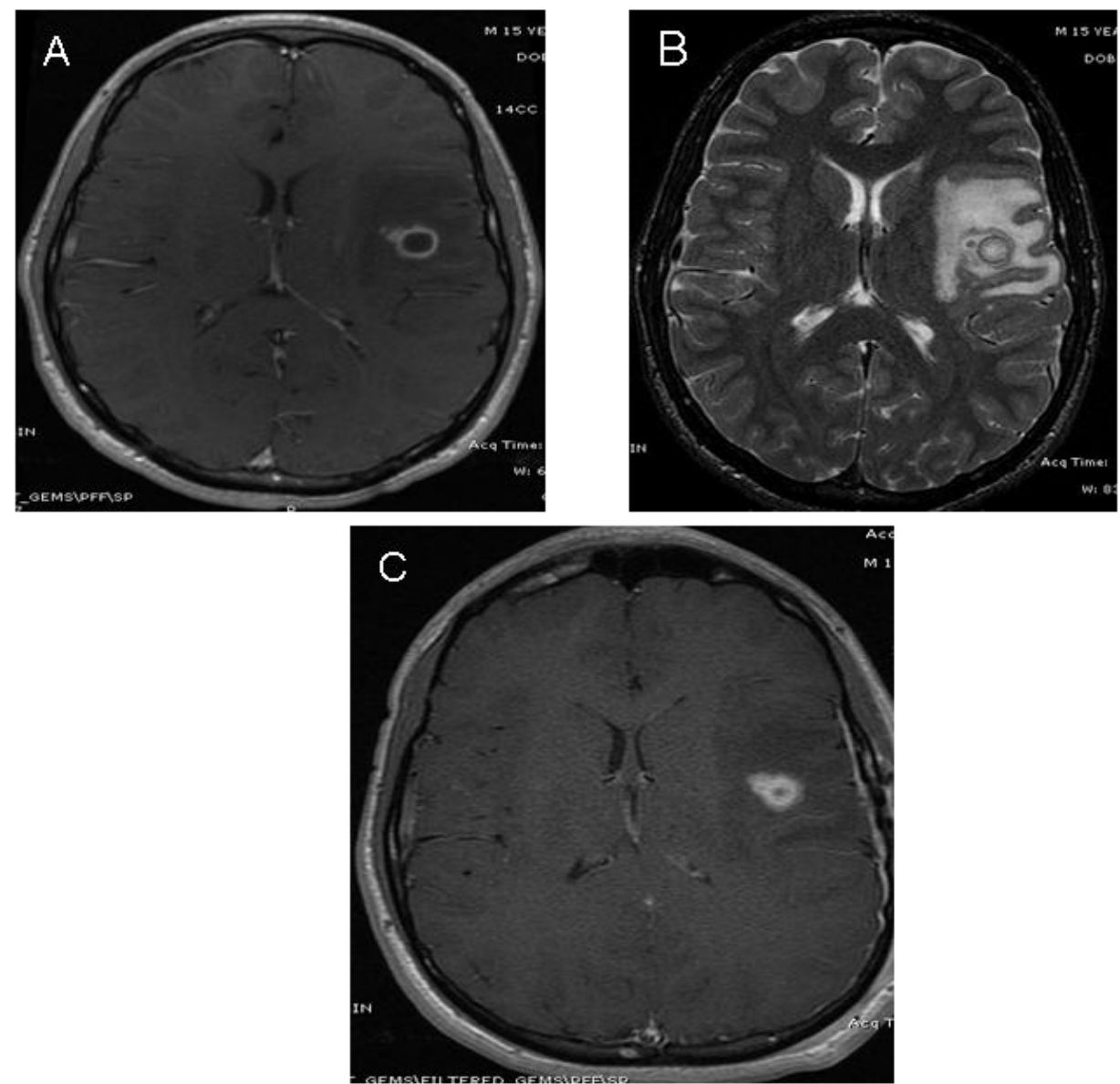

FIG. 1. Axial MR images obtained in a 15-year-old boy who presented with right-sided numbness and slurred speech. His neurological examination was significant for slight dysarthria. A head CT revealed a hypodense lesion in the left frontal lobe (not shown). A: Preoperative T1-weighted Gd-enhanced image demonstrating a ring-enhancing lesion in the left frontal lobe. B: Preoperative T2-weighted image showing the lesion to be hyperintense with surrounding vasogenic edema. C: Gadolinium-enhanced T1-weighted image obtained on postoperative Day 1 after a craniotomy and abscess drainage under ultrasonographic guidance. Residual enhancement is observed.

from cases performed with stereotactic aspiration in terms of the number of postoperative CT scans, length of hospital stay, and duration of antibiotic therapy. Further studies are needed to compare the efficacy of neuroendoscopy with stereotactic aspiration.

\section{Lesion Location}

Cerebrum. The optimal management of intracerebral abscesses varies according to lesion size, location, and stage. Stereotactic aspiration may be performed for abscesses in the cerebritis stage. Lesions $<2.5 \mathrm{~cm}$ in diameter may be managed with antibiotics and stereotactic aspiration for identification of a microorganism, while a diameter $>2.5$ $\mathrm{cm}$ may warrant stereotactic aspiration or surgical excision, contigent on proximity to or location within the eloquent cortex. Stereotactic aspiration of deep-seated abscesses may be more appropriate, and judicious management must be used in the treatment of lesions located in critical areas, such as in speech areas and the motor cortex. Large abscesses with a significant mass effect should be decompressed through the safest treatment modality, such as stereotactic aspiration for abscesses located in eloquent areas.
Cerebellum. Cerebellar abscesses are usually resected via craniotomy, especially when the lesion is associated with mass effect, edema, and/or obstructive hydrocephalus. However, controversy persists over the optimal management: stereotactic aspiration or surgical extirpation. ${ }^{2}$ A large size and/or the presence of edema can have a pronounced effect due to the small volume of the posterior fossa. The condition of neurologically intact patients can rapidly deteriorate to a comatose state due to obstructive hydrocephalus and/or mass effect on the brainstem., ${ }^{2,12,42,103}$ A wide decompression of the posterior fossa has been advocated because of the precarious state of a cerebellar abscess in the small volume of the posterior fossa. ${ }^{2,39}$ In 1973, Bhatia et al. ${ }^{8}$ reviewed 55 cases of brain abscesses, in which 11 were located in the posterior fossa. The mortality rate was 50\% among patients treated with aspiration, compared with $15 \%$ after surgical excision. In 1975, another study demonstrated surgical excision of cerebellar abscesses to be marginally better than aspiration. ${ }^{94}$ In a report published in 1994, Brydon and Hardwidge ${ }^{12}$ found that patients who underwent resection for brain abscess did not need subsequent surgical treatment for hydrocephalus, in contrast to some of those who underwent aspiration. This find- 

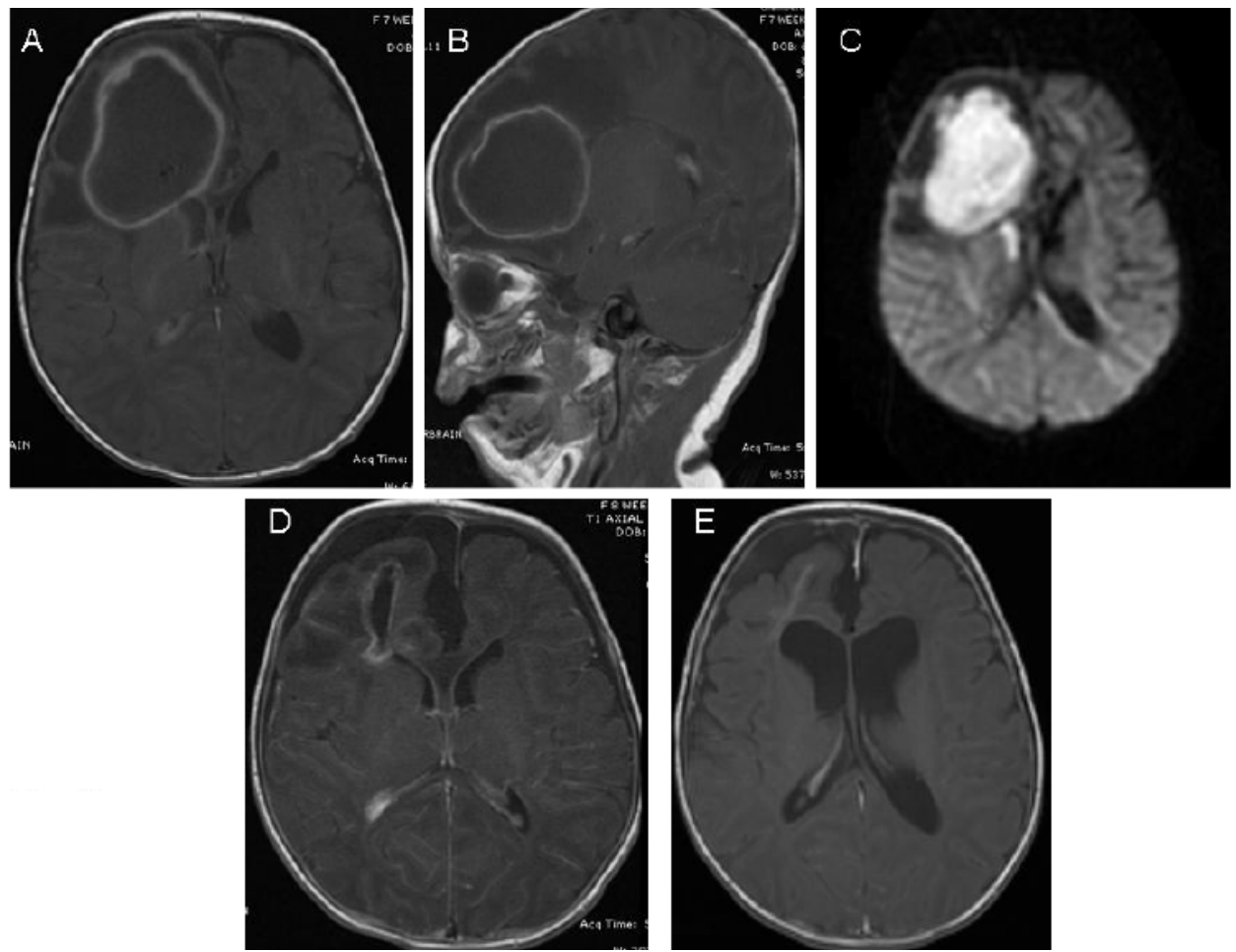

FIG. 2. Images obtained in a 7-week-old girl who presented with persistent fevers. Subsequent imaging revealed a large right frontal abscess. A and B: Preoperative axial and sagittal T1-weighted, contrast-enhanced MR images demonstrating a large ring-enhancing lesion in the right frontal lobe. C: Preoperative diffusion-weighted image revealing restricted diffusion. D: Axial, contrast-enhanced, T1-weighted, MR image obtained immediately after the infant underwent bur hole drainage of the abscess. A reduction in the size of the abscess is noted. E: Postoperative, contrastenhanced, T1-weighted axial MR image obtained 4 weeks postsurgery demonstrating resolution of the abscess with mild residual enhancement. The identified organism was Citrobacter.

ing was statistically significant. Agrawal et al. ${ }^{2}$ reported on the cases of 9 children who underwent surgical excision of cerebellar abscesses, and there were no deaths in their series. Hydrocephalus developed in 3 of their patients, but only 1 required shunt placement for cerebrospinal fluid diversion. They concluded from their results-albeit a small series-that primary excision can significantly reduce complications, deaths, and hospital costs due to shorter hospital stays. Moreover, in cerebellar abscesses caused by otogenic abscesses secondary to chronic otitis media, operative planning for a mastoidectomy with an otolaryngologist should be done to coordinate the timing of treatment for each lesion, although much debate remains as to whether the mastoidectomy should be performed preoperatively, concurrently, or postoperatively in cases in which a craniotomy is performed for the cerebellar abscess. ${ }^{2,56,94,95,109}$

Brainstem. Brainstem abscesses are generally treated with stereotactic aspiration and antibiotic therapy, although there are no concrete data about the optimal management. Fewer than $1 \%$ of brain abscesses are located in the brainstem, and these were considered lethal prior to $1974 .{ }^{7,44}$, 78,85,99,106 Since 1974, 12 children who underwent treatment for brainstem abscesses with stereotactic aspiration, microsurgery, or antibiotic therapy alone have been reported with good outcomes. ${ }^{20,34,45,47,52,66,72,78,85,99,104,105}$ Stereotactic drainage has been performed through the right paramedian precoronal frontal or suboccipital transcerebellar approaches. . $3,71,72^{2}$
Potential problems associated with the stereotactic aspiration of brain abscesses include incomplete evacuation because of thick purulent materal or multiloculations, and/or hemorrhage of the abscess capsule.$^{87,99}$ Open microsurgery can reduce mass effect on the brainstem and provides direct visual control of the collapse of the abscess as an indication of complete evacuation of the pus; penetration of the abscess at the point of the highest fluctuation decreases the risk of brain stem damage. ${ }^{47,99}$ High-risk surgical patients or neurologically stable patients with a brainstem abscess of $<2 \mathrm{~cm}$ diameter may be treated medically with antibiotic therapy and serial imaging follow-up.

\section{Management of Multiple Brain Abscesses}

The management of patients with multiple brain abscesses has generated much debate, and the incidence is reported at $10-50 \% .{ }^{19}$ Stereotactic aspiration or surgical excision should be performed for abscesses larger than $2.5 \mathrm{~cm}$ or smaller lesions that are causing a significant mass effect. If there are no abscesses larger than $2.5 \mathrm{~cm}$ in diameter, then the largest abscess should be stereotactically aspirated for the purpose of cultures. ${ }^{63}$ The duration of the antibiotics course is usually 6-8 weeks and longer for immunocompromised patients. Serial imaging is conducted on a weekly basis or immediately if there is a decline in the patient's neurological status. A decline in the patient's clinical status, enlargement of the abscess after 2 weeks of antibiotics, or 

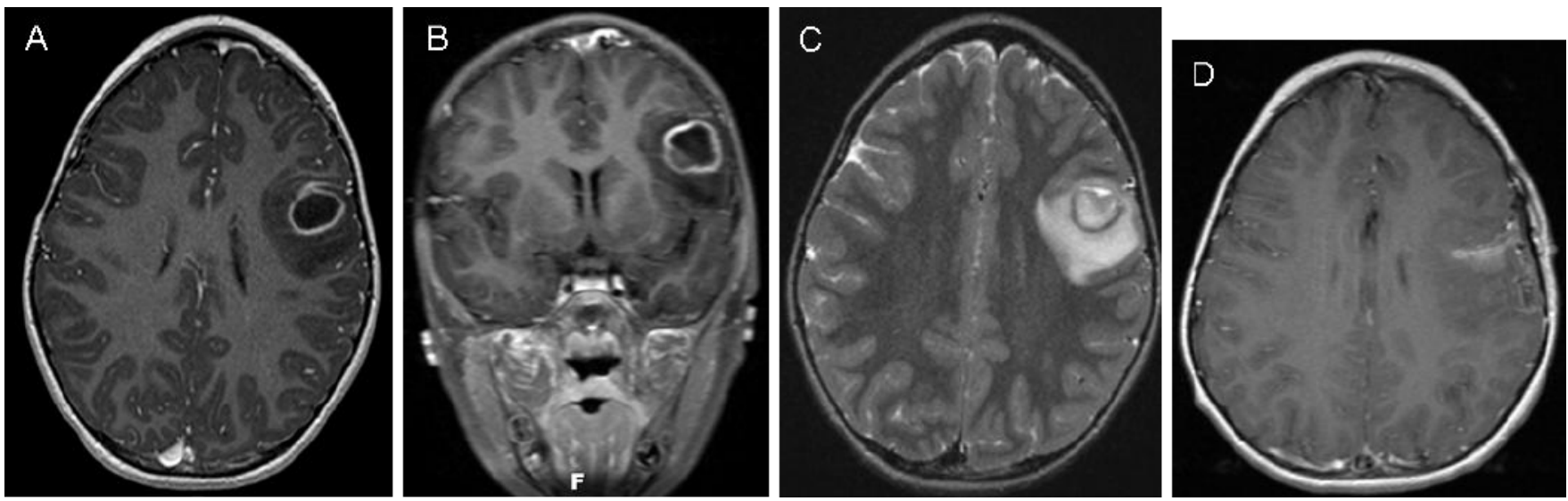

FIG. 3. Images obtained in a 6-year-old boy who developed focal seizures marked by dysarthria which generalized into a grand mal seizure. His neurological examination was significant for dysarthria and right-sided weakness. A and B: Preoperative axial and coronal contrast-enhanced, T1-weighted MR images demonstrating a ring-enhancing lesion in the left frontal lobe. C: Preoperative T2-weighted axial MR image demonstrating the hyperintense lesion in the left frontal lobe with surrounding vasogenic edema. D: Contrast-enhanced, T1-weighted axial MR image obtained after craniotomy and drainage of the abscess.

the observation of no reduction in the size of the abscess after 4 weeks of antibiotic therapy should warrant a repeated operation. ${ }^{19}$

\section{Management of Recurrent Brain Abscesses}

Abscess recurrence has been found to be more common after aspiration than surgical extirpation. The incidence after stereotactic aspiration ranges from 3-25\% compared with $0-6 \%$ after excision. ${ }^{73}$ Medical management alone of large abscesses is usually inadequate and tends to lead to recurrence. Aspiration of some fungal abscesses may require repeated operation via surgical excision. Brain abscesses secondary to cranial trauma tend to recur if surgical excision is not performed because the bone fragments and/or foreign bodies are retained. Additionally, the lack of appropriate antimicrobial coverage for the abscess and/or failure to treat the sources of the infection can predispose patients to recurrence.

\section{Role of Imaging During Treatment}

Serial imaging studies are crucial in assessing the efficacy of treatment. Interval CT or MR images should be obtained to examine the imaging characteristics of the abscesses on a weekly or biweekly schedule. Complete resolution of the abscess and associated abnormal contrast enhancement may take up to 12-16 weeks, and a small area of residual contrast enhancement may be present for up to 6 months after antibiotic therapy alone or in combination with stereotactic aspiration or surgical drainage via craniotomy (Fig. 3). ${ }^{19,88}$ The size of the abscess decreases in 1-4 weeks with antibiotic therapy alone or in combination with stereotactic aspiration, and 95\% of abscesses that resolve with antibiotic treatment alone demonstrate a reduction in size within a month. ${ }^{19}$

\section{Seizures}

Seizures occur in $10-72 \%$ of patients with brain abscesses and in up to $50-70 \%$ of patients treated with surgical excision. ${ }^{58,74}$ In a majority of children with brain abscesses, the onset of seizures is delayed, with only $50 \%$ occurring within the first year after treatment. ${ }^{14}$ Legg et al. ${ }^{58}$ reported that initial seizures appear to occur after a longer latency period in children younger than 10 years old. It has been reported that the mean latency period is $\sim 3$ years, and anticonvulsant agents are generally efficacious in controlling seizures. Early aspiration is advocated in infants because of the propensity for early seizures with meningitis and hydrocephalus, all of which portend a poor prognosis. ${ }^{19}$ Perioperative and postoperative medical antiepileptic therapy is generally recommended, and the duration of this therapy should be tailored individually.

\section{Prognosis}

Although there have been significant advances in the treatment and diagnosis of brain abscesses, the associated rates of mortality and morbidity continue to be significant. The overall outcome in children with brain abscesses is determined by a myriad of factors, such as the virulence of the pathogen, the location and number of the abscesses, the underlying source of infection, and the clinical status of the patient at the time of presentation. The patient's neurological status at presentation has been shown to be a significant predictor of outcome with an increased mortality rate in those who present with altered mental status and rapid neurological deterioration. ${ }^{64,88,89,107}$ Prior to the antibiotic era, the mortality rate ranged from 40 to $60 \%$. With the advent of antimicrobial agents, improved culturing techniques, and imaging modalities leading to earlier detection and better surgical localization, current death rates have been reported in the $4-12 \%$ range. ${ }^{19,22,64} \mathrm{~A}$ large number of the complications and deaths in children with brain abscesses may be attributable to multiple abscesses, the presence of low Glascow Coma Scale scores, and/or meningitis. ${ }^{19}$ Moreover, many authors have reported that brain abscesses in children cause cognitive deficits..$^{14,15,19}$ These authors also document that a poorer prognosis in terms of normal intellectual development is expected in younger children 
with brain abscesses. Because earlier detection may affect rates of morbidity and mortality, children with neurological deficits, altered mental status, headaches, and/or seizures should be evaluated for a brain abscess, particularly if the patient has a predisposing factor such as sinusitis, congenital heart disease, otitis media, or an immunocompromised state.

Overall, a worse prognosis has been found in patients with multiple deep-seated and/or large abscesses, intraventricular rupture, congenital heart disease, hydrocephalus, poor neurological status, and associated meningitis. Neonates and infants have a much worse prognosis, as do those in whom there was an initial error in diagnosis and/or an unknown source of infection. ${ }^{9,49,61,64,93,97,101,102,111}$

\section{Conclusions}

Although brain abscesses arise infrequently in children, the rates of morbidity and mortality in this population are significant. Advances in antibiotic therapy, culturing procedures, and operative techniques, combined with earlier detection made possible through the development of imaging modalities have led to significant progress in the treatment of this disease. Clinicians should have a high clinical index of suspicion for brain abscesses in children with seizures, persistent fevers, alterations in mental status, headaches, neurological deficits, a known source of infection, an immunocompromised state, history of head trauma, and/or congenital heart disease. The high clinical index of suspicion is important because earlier detection may improve outcome. A multidisciplinary team approach, including neurosurgeons, pediatricians, and infectious disease specialists, should be utilized when these lesions are encountered in children. Stereotactic-guided aspiration is useful, but endoscopic drainage may be used more frequently in the future as a greater number of surgeons become comfortable with this technique, as it allows direct visualization during drainage of the purulent material. Craniotomy for this entity should be performed in the appropriate clinical context, taking into consideration various factors including multiloculated abscesses, traumatic head injuries, recurrences after multiple aspirations, fungal abscesses, and cerebellar lesions with significant mass effect, among others. During the treatment regimen, serial imaging is important in the assessment of efficacy. Ultimately, the multidisciplinary team must tailor the treatment based upon the clinical scenario of a patient, with the neurosurgeon playing a vital role in determining the type of operative procedures to be performed, if any.

\section{References}

1. Agarwal A, Gergits F III, Isaacson G: Metastatic intracranial abscesses of bronchopulmonary origin. Pediatr Infect Dis J 22: 277-280, 2003

2. Agrawal D, Suri A, Mahapatra AK: Primary excision of pediatric posterior fossa abscesses - towards zero mortality? A series of nine cases and review. Pediatr Neurosurg 38:63-67, 2003

3. Bambakidis NC, Cohen AR: Intracranial complications of frontal sinusitis in children: Pott's puffy tumor revisited. Pediatr Neurosurg 35:82-89, 2001

4. Bank DE, Carolan PL: Cerebral abscess formation following ocular trauma: a hazard associated with common wooden toys. Pediatr Emerg Care 9:285-288, 1993
5. Bavetta S, Paterakis K, Srivatsa SR, Garvan N: Brainstem abscess: preoperative MRI appearance and survival following stereotactic aspiration. J Neurosurg Sci 40:139-143, 1996

6. Bellotti C, Aragno MG, Medina M, Viglietti AL, Oliveri G, Ettorre F, et al: Differential diagnosis of CT-hypodense cranial lesions with indium-111-oxine-labeled leukocytes. J Neurosurg 64:750-753, 1986

7. Berg B, Franklin G, Cuneo R, Boldrey E, Strimling B: Nonsurgical cure of brain abscess: early diagnosis and follow-up with computerized tomography. Ann Neurol 3:474-478, 1978

8. Bhatia R, Tandon PN, Banerji AK: Brain abscess-an analysis of 55 cases. Int Surg 58:565-568, 1973

9. Bidzinski J, Koszewski W: The value of different methods of treatment of brain abscess in the CT era. Acta Neurochir (Wien) 105:117-120, 1990

10. Britt RH: Brain abscess, in Wilkins RH, Rengachary SS (eds): Neurosurgery. New York: McGraw-Hill, 1985, Vol 3, pp 1928-1956

11. Britt RH, Enzmann DR, Yeager AS: Neuropathological and computerized tomographic findings in experimental brain abscess. J Neurosurg 55:590-603, 1981

12. Brydon HL, Hardwidge C: The management of cerebellar abscess since the introduction of CT scanning. Br $\mathbf{J}$ Neurosurg 8: 447-455, 1994

13. Bükte Y, Paksoy Y, Genç E, Uca AU: Role of diffusion-weighted MR in differential diagnosis of intracranial cystic lesions. Clin Radiol 60:375-383, 2005

14. Buonaguro A, Colangelo M, Daniele B, Cantone G, Ambrosio A: Neurological and behavioral sequelae in children operated on for brain abscess. Childs Nerv Syst 5:153-155, 1989

15. Carey ME, Chou SN, French LA: Experience with brain abscesses. J Neurosurg 36:1-9, 1972

16. Carpenter JL: Brain stem abscesses: cure with medical therapy, case report, and review. Clin Infect Dis 18:219-226, 1994

17. Chacko AG, Chandy MJ: Diagnostic and staged stereotactic aspiration of multiple bihemispheric pyogenic brain abscesses. Surg Neurol 48:278-283, 1997

18. Chun CH, Johnson JD, Hofstetter M, Raff MJ: Brain abscess. A study of 45 consecutive cases. Medicine (Baltimore) 65: 415-431, 1986

19. Ciurea AV, Stoica F, Vasilescu G, Nuteanu L: Neurosurgical management of brain abscesses in children. Childs Nerv Syst 15: 309-317, 1999

20. Danziger J, Allen KL, Bloch S: Brain-stem abscess in childhood. Case report. J Neurosurg 40:391-393, 1974

21. de Oliveira RS, Pinho VF, Madureira JF, Machado HR: Brain abscess in a neonate: an unusual presentation. Childs Nerv Syst 23:139-142, 2007

22. Donald FE, Firth JL, Holland IM, Hope DT, Ispahani P, Punt JA: Brain abscess in the 1980s. Br J Neurosurg 4:265-271, 1990

23. Dubey SP, Larawin V: Complications of chronic suppurative otitis media and their management. Laryngoscope 117:264-267, 2007

24. Dyste GN, Hitchon PW, Menezes AH, VanGilder JC, Greene GM: Stereotaxic surgery in the treatment of multiple brain abscesses. J Neurosurg 69:188-194, 1988

25. Enzmann DR, Britt RH, Yeager AS: Experimental brain abscess evolution: computed tomographic and neuropathologic correlation. Radiology 133:113-122, 1979

26. Erol I, Cetin, II, Alehan F, Varan B, Ozkan S, Agildere AM, et al: Brain abscess associated with isolated left superior vena cava draining into the left atrium in the absence of coronary sinus and atrial septal defect. Cardiovasc Intervent Radiol 29:454-456, 2006

27. Ersahin Y, Mutluer S, Güzelbag E: Brain abscess in infants and children. Childs Nerv Syst 10:185-189, 1994

28. Ersahin Y, Mutluer S, Mirzai H, Palali I: Pediatric depressed skull fractures: analysis of 530 cases. Childs Nerv Syst 12:323-331, 1996 
29. Ersahin Y, Yurtseven T: Rare complications of shunt infection. Pediatr Neurosurg 40:90-92, 2004

30. Fanning NF, Laffan EE, Shroff MM: Serial diffusion-weighted MRI correlates with clinical course and treatment response in children with intracranial pus collections. Pediatr Radiol 36:26-37, 2006

31. Fischer G, Goebel H, Latta E: Penetration of the colon by a ventriculo-peritoneal drain resulting in an intra-cerebral abscess. Zentralbl Neurochir 44:155-160, 1983

32. Foy P, Sharr M: Cerebral abscesses in children after pencil-tip injuries. Lancet 2:662-663, 1980

33. Fritsch M, Manwaring KH: Endoscopic treatment of brain abscess in children. Minim Invasive Neurosurg 40:103-106, 1997

34. Fuentes S, Bouillot P, Regis J, Lena G, Choux M: Management of brain stem abscess. Br J Neurosurg 15:57-62, 2001

35. Gaillard T, Gilsbach JM: Intra-operative antibiotic prophylaxis in neurosurgery. A prospective, randomized, controlled study on cefotiam. Acta Neurochir (Wien) 113:103-109, 1991

36. Goldberg AN, Oroszlan G, Anderson TD: Complications of frontal sinusitis and their management. Otolaryngol Clin North Am 34:211-225, 2001

37. Goodkin HP, Harper MB, Pomeroy SL: Intracerebral abscess in children: historical trends at Children's Hospital Boston. Pediatrics 113:1765-1770, 2004

38. Gower DJ, Horton D, Pollay M: Shunt-related brain abscess and ascending shunt infection. J Child Neurol 5:318-320, 1990

39. Griffith HB: Factors in mortality of cerebellar abscesses. J Neurol Neurosurg Psychiatry 31:89, 1968

40. Hakim HE, Malik AC, Aronyk K, Ledi E, Bhargava R: The prevalence of intracranial complications in pediatric frontal sinusitis. Int J Pediatr Otorhinolaryngol 70:1383-1387, 2006

41. Hellwig D, Bauer BL, Dauch WA: Endoscopic stereotactic treatment of brain abscesses. Acta Neurochir Suppl (Wien) 61:102-105, 1994

42. Hirsch JF, Roux FX, Sainte-Rose C, Renier D, Pierre-Kahn A: Brain abscess in childhood. A study of 34 cases treated by puncture and antibiotics. Childs Brain 10:251-265, 1983

43. Ho VH, Wilson MW, Fleming JC, Haik BG: Retained intraorbital metallic foreign bodies. Ophthal Plast Reconstr Surg 20: 232-236, 2004

44. Hulme A: Suppurative lesions of the brain-stem. J Neurol Neurosurg Psychiatry 24:291-293, 1961

45. Imai H, Ono N, Zama A, Tamura M: Diagnosis and treatment of brainstem abscess using magnetic resonance imaging and microsurgical aspiration—case report. Neurol Med Chir 35:160-164, 1995

46. Jadavji T, Humphreys RP, Prober CG: Brain abscesses in infants and children. Pediatr Infect Dis 4:394-398, 1985

47. Jamjoom ZA: Solitary brainstem abscess successfully treated by microsurgical aspiration. Br J Neurosurg 6:249-253, 1992

48. Jindal A, Kansal S, Mahapatra AK: Unusual complication-VP shunt coming out per rectum and brain abscess. Indian J Pediatr 66:463-465, 1999

49. Joshi SM, Devkota UP: The management of brain abscess in a developing country: are the results any different? Br J Neurosurg 12:325-328, 1998

50. Kamikawa S, Inui A, Miyake S, Kobayashi N, Kasuga M, Yamadori T, et al: Neuroendoscopic surgery for brain abscess. Eur J Paediatr Neurol 1:121-122, 1997

51. Kaplan D: Brain abscess. Med Clin North Am 69:345-360, 1985

52. Kashiwagi S, Abiko S, Aoki H: Brainstem abscess. Surg Neurol 28:63-66, 1987

53. Krajewski R, Stelmasiak Z: Brain abscess in infants. Childs Nerv Syst 8:279-280, 1992

54. Kumar K: Neurological complications of congenital heart disease. Indian J Pediatr 67:287-291, 2000

55. Kumar K: Neurological complications of congenital heart disease. Indian J Pediatr 67 (3 Suppl): S15-19, 2000
56. Kurien M, Job A, Mathew J, Chandy M: Otogenic intracranial abscess: concurrent craniotomy and mastoidectomy - changing trends in a developing country. Arch Otolaryngol Head Neck Surg 124:1353-1356, 1998

57. Lai PH, Hsu SS, Ding SW, Ko CW, Fu JH, Weng MJ, et al: Proton magnetic resonance spectroscopy and diffusion-weighted imaging in intracranial cystic mass lesions. Surg Neurol 68 (1 Suppl): S25-S36, 2007

58. Legg NJ, Gupta PC, Scott DF: Epilepsy following cerebral abscess. A clinical and EEG study of 70 patients. Brain 96: 259-268, 1973

59. Liston TE, Tomasovic JJ, Stevens EA: Early diagnosis and management of cerebritis in a child. Pediatrics 65:484-486, 1980

60. Longatti P, Perin A, Ettorre F, Fiorindi A, Baratto V: Endoscopic treatment of brain abscesses. Childs Nerv Syst 22:1447-1450, 2006

61. Lu CH, Chang WN, Lui CC: Strategies for the management of bacterial brain abscess. J Clin Neurosci 13:979-985, 2006

62. Macewen M: Pyogenic Infection Diseases of the Brain and Spinal Cord: Meningitis, Abscess of Brain, Infective Sinus Thrombosis. New York: MacMillan \& Co, 1893

63. Mamelak AN, Mampalam TJ, Obana WG, Rosenblum ML: Improved management of multiple brain abscesses: a combined surgical and medical approach. Neurosurgery 36: 76-86, 1995

64. Mampalam TJ, Rosenblum ML: Trends in the management of bacterial brain abscesses: a review of 102 cases over 17 years. Neurosurgery 23:451-458, 1988

65. Mathisen GE, Johnson JP: Brain abscess. Clin Infect Dis 25: 763-781, 1997

66. Messina AV, Guido LJ, Liebeskind AL: Preoperative diagnosis of brain-stem abscess by computerized tomography with survival. Case report. J Neurosurg 47:106-108, 1977

67. Miller ES, Dias PS, Uttley D: CT scanning in the management of intracranial abscess: a review of 100 cases. Br J Neurosurg 2: 439-446, 1988

68. Mises J, Daviet F, Moussalli-Salefranque F, Sternberg B, Flandin C, Renier D: [Brain abscess in the newborn infant (27 cases: initial electroclinical study, course.] Rev Electroencephalogr Neurophysiol Clin 17:301-308, 1987 (Fr)

69. Mishra AM, Gupta RK, Saksena S, Prasad KN, Pandey CM, Rathore D, et al: Biological correlates of diffusivity in brain abscess. Magn Reson Med 54:878-885, 2005

70. Mortimore S, Wormald PJ: Management of acute complicated sinusitis: a 5-year review. Otolaryngol Head Neck Surg 121: 639-642, 1999

71. Nakajima H, Iwai Y, Yamanaka K, Kishi H: Successful treatment of brainstem abscess with stereotactic aspiration. Surg Neurol 52:445-448, 1999

72. Nauta HJ, Contreras FL, Weiner RL, Crofford MJ: Brain stem abscess managed with computed tomography-guided stereotactic aspiration. Neurosurgery 20:476-480, 1987

73. Neuwelt EA, Lawrence MS, Blank NK: Effect of gentamicin and dexamethasone on the natural history of the rat Escherichia coli brain abscess model with histopathological correlation. Neurosurgery 15:475-483, 1984

74. Obana WG, Rosenblum ML: Surgery for intracranial infections, in Post KD, Friedman E, McCormick P (eds): Postoperative Complications of Neurological Surgery. New York: Thieme Medical, 1993, pp 146-156

75. Palestro CJ, Swyer AJ, Kim CK, Muzinic M, Goldsmith SJ: Role of in-111 labeled leukocyte scintigraphy in the diagnosis of intracerebral lesions. Clin Nucl Med 16:305-308, 1991

76. Panagea S, Cartmill TD, Panigrahi H: Intracerebral sepsis due to intestinal perforation by ventriculo-peritoneal shunts: two cases. J Infect 35:86-88, 1997

77. Quartey GR, Johnston JA, Rozdilsky B: Decadron in the treatment of cerebral abscess. An experimental study. J Neurosurg 45:301-310, 1976 
78. Rajshekhar V, Chandy MJ: Successful stereotactic management of a large cardiogenic brain stem abscess. Neurosurgery 34:368-371, 1994

79. Reddy JS, Mishra AM, Behari S, Husain M, Gupta V, Rastogi M, et al: The role of diffusion-weighted imaging in the differential diagnosis of intracranial cystic mass lesions: a report of 147 lesions. Surg Neurol 66:246-2501, 2006

80. Renier D, Flandin C, Hirsch E, Hirsch JF: Brain abscesses in neonates. A study of 30 cases. J Neurosurg 69:877-882, 1988

81. Rish BL, Caveness WF, Dillon JD, Kistler JP, Mohr JP, Weiss $\mathrm{GH}$ : Analysis of brain abscess after penetrating craniocerebral injuries in Vietnam. Neurosurgery 9:535-541, 1981

82. Roberts J, Bartlett AH, Giannoni CM, Valdez TA: Airway foreign bodies and brain abscesses: report of two cases and review of the literature. Int J Pediatr Otorhinolaryngol 72:265-269, 2008

83. Rosenblum ML, Hoff JT, Norman D, Weinstein PR, Pitts L: Decreased mortality from brain abscesses since advent of computerized tomography. J Neurosurg 49:658-668, 1978

84. Rosenblum ML, Mampalam TJ, Pons VG: Controversies in the management of brain abscesses. Clin Neurosurg 33:603-632, 1986

85. Russell JA, Shaw MD: Chronic abscess of the brain stem. J Neurol Neurosurg Psychiatry 40:625-629, 1977

86. Samson DS, Clark K: A current review of brain abscess. Am J Med 54:201-210, 1973

87. Sarma S, Sekhar LN: Brain-stem abscess successfully treated by microsurgical drainage: a case report. Neurol Res 23:855-861, 2001

88. Schmidek HH: Suppurative intracranial infections, in Schmidek HH, Roberts DW (eds): Schmidek \& Sweet Operative Neurosurgical Techniques. Indications, Methods, and Results, ed 5. Philadelphia: Elsevier, Inc, 2006, pp 1591-1599

89. Seydoux C, Francioli P: Bacterial brain abscesses: factors influencing mortality and sequelae. Clin Infect Dis 15:394-401, 1992

90. Shahzadi S, Lozano AM, Bernstein M, Guha A, Tasker RR: Stereotactic management of bacterial brain abscesses. Can J Neurol Sci 23:34-39, 1996

91. Sharma BS, Gupta SK, Khosla VK: Current concepts in the management of pyogenic brain abscess. Neurol India 48:105-111, 2000

92. Sharma BS, Kak VK: Multiple subdural abscesses following colonic perforation - a rare complication of a ventriculoperitoneal shunt. Pediatr Radiol 18:407-408, 1988

93. Sharma BS, Khosla VK, Kak VK, Gupta VK, Tewari MK, Mathuriya SN, et al: Multiple pyogenic brain abscesses. Acta Neurochir (Wien) 133:36-43, 1995

94. Shaw MD, Russell JA: Cerebellar abscess. A review of 47 cases. J Neurol Neurosurg Psychiatry 38:429-435, 1975

95. Singh B, Maharaj TJ: Radical mastoidectomy: its place in otitic intracranial complications. J Laryngol Otol 107:1113-1118, 1993

96. Skrap M, Melatini A, Vassallo A, Sidoti C: Stereotactic aspiration and drainage of brain abscesses. Experience with 9 cases. Minim Invasive Neurosurg 39:108-112, 1996
97. Stephanov S: Surgical treatment of brain abscess. Neurosurgery 22:724-730, 1988

98. Sutton DL, Ouvrier RA: Cerebral abscess in the under 6 month age group. Arch Dis Child 58:901-905, 1983

99. Suzer T, Coskun E, Cirak B, Yagci B, Tahta K: Brain stem abscesses in childhood. Childs Nerv Syst 21:27-31, 2005

100. Szuwart U, Bennefeld H: Bacteriological analysis of pyogenic infections of the brain. Neurosurg Rev 13:113-118, 1990

101. Takeshita M, Kagawa M, Yato S, Izawa M, Onda H, Takakura $\mathrm{K}$, et al: Current treatment of brain abscess in patients with congenital cyanotic heart disease. Neurosurgery 41:1270-1279, 1997

102. Tekkök IH, Erbengi A: Management of brain abscess in children: review of 130 cases over a period of 21 years. Childs Nerv Syst 8:411-416, 1992

103. van Dellen JR, Bullock R, Postma MH: Cerebellar abscess: the impact of computed tomographic scanning. Neurosurgery 21:547-550, 1987

104. Vaquero J, Cabezudo JM, Leunda G: Nonsurgical resolution of a brain-stem abscess. Case report. J Neurosurg 53:726-727, 1980

105. Wang HS, Kuo MF, Huang SC: Medical cure of a brainstem abscess and serial brainstem auditory evoked potentials. Dev Med Child Neurol 34:911-915, 1992

106. Weickhardt GD, Davis RL: Solitary abscess of the brainstem. Neurology 14:918-925, 1964

107. Wispelwey B, Scheld WM: Brain abscess, in Mandell GL, Bennett JE, Dolin R (eds): Principles and Practice of Infectious Diseases, ed 4. New York: Churchill Livingstone, 1995, pp 887-900

108. Wong TT, Lee LS, Wang HS, Shen EY, Jaw WC, Chiang CH, et al: Brain abscesses in children-a cooperative study of 83 cases. Childs Nerv Syst 5:19-24, 1989

109. Wright JL, Grimaldi PM: Otogenic intracranial complications. J Laryngol Otol 87:1085-1096, 1973

110. Xiao F, Tseng MY, Teng LJ, Tseng HM, Tsai JC: Brain abscess: clinical experience and analysis of prognostic factors. Surg Neurol 63:442-450, 2005

111. Yang SY: Brain abscess: a review of 400 cases. J Neurosurg 55:794-799, 1981

112. Zeidman SM, Geisler FH, Olivi A: Intraventricular rupture of a purulent brain abscess: case report. Neurosurgery 36: 189-193, 1995

Manuscript submitted January 15, 2008.

Accepted March 11, 2008.

Address correspondence to: James L. Frazier, M.D., Department of Neurosurgery, Meyer 8-161, Johns Hopkins Hospital, 600 North Wolfe Street, Baltimore, Maryland 21287. email: jfrazier@ jhmi.edu. 